\title{
Effect of substrate type and pellet age on the resuspension of Atlantic salmon faecal material
}

\author{
M. A. Carvajalino-Fernández ${ }^{1,2, *}$, N. B. Keeley ${ }^{1}$, I. Fer ${ }^{2}$, B. A. Law ${ }^{3}$, R. J. Bannister ${ }^{1}$ \\ ${ }^{1}$ Institute of Marine Research, 5817 Bergen, Norway \\ ${ }^{2}$ Geophysical Institute, University of Bergen, 5020 Bergen, Norway \\ ${ }^{3}$ Fisheries and Oceans Canada, Bedford Institute of Oceanography, Dartmouth, Nova Scotia B2Y 4A2, Canada
}

\begin{abstract}
The influence of substrate type and particle age on the remobilization of settled Atlantic salmon Salmo salar faecal material was studied through a set of controlled experiments in horizontal flow flumes, simulating different bottom conditions present in fish-farming locations along the coast of Norway. There was no significant effect of pellet age on remobilization for up to 1 week old faecal material, but critical shear stresses $\left(\tau_{c}\right)$ and velocities required for resuspending faecal pellets were strongly dependent on substrate type. Smooth substrates such as mud and rock slate required lower stresses for the onset of faeces resuspension $\left(\tau_{c} \approx 0.06 \mathrm{~Pa}\right)$ than rougher surfaces such as sand $\left(\tau_{c} \approx 0.12 \mathrm{~Pa}\right)$ or fragmented rock $\left(\tau_{c} \approx 0.32 \mathrm{~Pa}\right)$, where bedforms and large fractures shield the particles from the direct influence of the drag forces. These newly determined substrate-dependent $\tau_{c}$ resuspension thresholds will contribute to the construction of more accurate numerical models that include bottom type as a parameter regulating the extent of particle spreading, in contrast to the constant-value approach that has been used to date.
\end{abstract}

KEY WORDS: Benthic boundary layer $\cdot$ Resuspension $\cdot$ Parametrization

\section{INTRODUCTION}

Fish and other marine organisms play an essential role in food security and nutrition in the context of climate change (FAO 2018). However, capture fisheries have proven insufficient to cope with the everincreasing demand from the global population. The growing aquaculture industry has thus become fundamental in covering the supply-demand gap for fish-related products during the past decades (Garcia \& Grainger 2005, World Bank 2013).

Norway has privileged conditions for marine aquaculture, with highly productive and suitable sites for fish farming along its entire coastline, making it the world's second largest exporter of seafood (Norwegian Ministry of Fisheries and Coastal Affairs 2009, Olafsen et al. 2012). Among the cultured species, Atlantic salmon Salmo salar dominates the industry due to its high market price and well-studied production

${ }^{*}$ Corresponding author: marcos.carvajalino.fernandez@hi.no cycle in captivity. Projections show that combined production of salmon and trout in Norway will expand to an annual production of 5 million tons by 2050 (Olafsen et al. 2012).

Growth in aquaculture production, especially using high-intensity systems such as those used for salmon, causes a variety of negative impacts to the surrounding ecosystems that have been widely studied during previous decades (Wu 1995, Black 2001, Martinez-Porchas \& Martinez-Cordova 2012). Ecosystems are directly affected by both particulate and suspended metabolism sub-products, such as faeces, pseudo-faeces and fish excretion, as well as excess feeding material not consumed by fish inside the cages (Silvert \& Sowles 1996, Brooks \& Mahnken 2003, Cubillo et al. 2016). All these wastes contain substantial amounts of organic carbon and nutrients that enrich both the water column and the seabed, causing changes in the sediment's biogeochemistry and

() M. A. C.-F., N. B. K., I. F., B. A. L., R. J. B., Institute of Marine Research, Fisheries and Oceans Canada 2020. Open Access under Creative Commons by Attribution Licence. Use, distribution and reproduction are unrestricted. Authors and original publication must be credited.

Publisher: Inter-Research · www.int-res.com 
the abundance and number of bottom-dwelling species (Reid et al. 2009, Bannister et al. 2014, Keeley et al. 2019). Impacts decrease gradually from the farm location to a point along the residual velocity direction where conditions no longer differ significantly from background conditions, encompassing an area that is usually referred to as the farm footprint (Pearson \& Rosenberg 1978, Keeley et al. 2013b).

Accurately determining the extent of the farm footprint is one of the biggest challenges in aquaculture impact studies. These studies usually involve the use of a coupled modelling system, comprising a hydrodynamic model that simulates the currents in the area of interest and a transport module that determines the dispersion and fate of the wastes produced at the farm (Keeley et al. 2013a, Bannister et al. 2016, Johnsen et al. 2016, Broch et al. 2017). The transport module should include processes that influence the behavior of individual types of waste, requiring quantification and testing steps (e.g. via field observations or lab-scale tests) in order to parameterize the model correctly. However, most of these processes are, to date, not completely understood. In the case of marine aquaculture, fish faeces tend to be the largest component of the particle waste discharge (Kutti et al. 2007, Cubillo et al. 2016). Therefore, there is a need to expand the current body of knowledge regarding drivers of fish faeces dispersion and interactions with the surrounding biota once settled on the seabed.

Most forces driving particle dispersion, and consequently the footprint extent and bottom organic matter enrichment, arise from the hydrodynamic conditions at a farm's specific location (Stucchi et al. 2005). Among the physical factors affecting particle mobilization are the strength of the currents, the surface gravity wave intensity, turbulence, water depth, bottom slope and type of bottom substrate. The mechanisms through which these factors influence the advection of particles during the initial deposition step have been thoroughly described in the literature (e.g. Nielsen 1993, Kutti et al. 2007, Bannister et al. 2016). However, once the particles reach the seabed, a complete set of additional processes induce their remobilization as well as their eventual re-entrainment into the free-flow velocity fields above the benthic boundary layer (BBL) (Kaftori et al. 1995, Boudreau \& Jørgensen 2001, Luckner 2002).

The current body of literature concerning remobilization processes for fish faeces is, unfortunately, very limited. The most commonly cited reference in the field is Cromey et al. (2002b), who determined a critical shear stress $\left(\tau_{c}\right)$ of $0.018 \mathrm{~Pa}$ for the resuspen- sion of particulate fish farm wastes by calibration of a Lagrangian particle transport model against a fluorescent ultraviolet tracer. The use of this critical value is widespread in aquaculture impact studies, as it is 'hard-coded' in the popular model DEPOMOD (Cromey et al. 2002a), which has been successfully implemented at fish farms in both dispersive and non-dispersive locations (Wilding et al. 2012, Keeley et al. 2013a, Chang et al. 2014), as well as adapted to shellfish aquaculture (Weise et al. 2009).

Although the findings from Cromey et al. (2002b) may represent a milestone for aquaculture particle spread modelling, it has been reported that DEPOMOD results, calculated with the default value of $\tau_{C r}$ tend to largely overestimate erosion rates and material transport when compared with observations from real farming sites (Chamberlain \& Stucchi 2007, Keeley et al. 2013a, Chang et al. 2014). The error in modelled values may be due to the use of a dummy tracer instead of real fish-farm wastes in the calibration of the resuspension module. Alternatively, the error may be a consequence of the experiments being performed at a single location and therefore representative of only one substrate type (i.e. sandy mud), while the theoretical background for the BBL indicates that its structure and energy dissipation patterns are strongly dependent on the type and characteristics of the substrate (Boudreau \& Jørgensen 2001, Trowbridge \& Lentz 2018). Therefore, a substrate-specific set of erosion thresholds would be a more robust approach to represent the resuspension of particulate material on the seabed.

A recent study by Law et al. (2016) identified differences in $\tau_{C}$ for feed pellets and faecal material using a Gust Microcosm Erosion Chamber (GMEC) and 5 different bottom substrates, concluding that substrate texture plays a major role in the resuspension of fishfarming wastes. Law et al. (2016) calculated a single $\tau_{c}$ of approximately $0.01 \mathrm{~Pa}$ for incipient motion of the faecal material, and substrate-dependent $\tau_{c}$ for feed pellets ranging from 0.03 to $0.28 \mathrm{~Pa}$ for bottom material ranging from consolidated muds to cobbles.

The results of Law et al. (2016) stress the need to include substrate-dependent sets of $\tau_{c}$ values in existing particle-tracking models in order to simulate the spread of fish farming particle wastes more accurately. However, we see certain limitations in their study, such as the use of broken-down faecal material in the experiments, as well as turbidity measurements as indicators for particle resuspension, whereas video surveys have shown that most faecal material sits on the seabed as unbroken faeces (hereafter faecal pellets) with particle sizes on 
the order of several millimeters to a few centimeters (Bannister et al. 2016). At these sizes, larger-scale devices and direct observational methods might be preferred over GMECs for resuspension threshold definitions.

The aim of this study was to address the limitations in Law et al. (2016) and validate the effect of substrate type and particle age on the $\tau_{c}$ needed to resuspend the faecal material of Atlantic salmon. To achieve this, we performed a series of controlled resuspension experiments using horizontal-flow flumes with interchangeable bottom substrates and intact faecal pellets from a local research farm to replicate the most common bottom dynamics at commercial fishfarming sites in Norway.

\section{MATERIALS AND METHODS}

\subsection{Sampling of fish faeces}

Faecal material was collected from a $5 \times 5 \times 7 \mathrm{~m}$ (length, width, depth) salmon-rearing cage located at the Norwegian Institute of Marine Research (IMR) research fish farm in Smørdalen, Norway. The cage contained ca. 500 Atlantic salmon with a mean individual weight of ca. $2 \mathrm{~kg}$.

Sampling was carried out from October 2017 to May 2018 using a passive waste sampler consisting of a weighed polyethylene bucket with a surface area of approximately $0.3 \mathrm{~m}^{2}$. Holes were cut on the sides of the sampler and covered with $500 \mu \mathrm{m}$ plankton mesh to facilitate sample retrieval and reduce loss of and damage to the faecal sample, following the design by Bannister et al. (2016). The sampler was lowered to approximately $2 \mathrm{~m}$ below the preferred swimming depth of the fish (determined via echo-sounding) using a system of ropes and pulleys.

Sampling started approximately $15 \mathrm{~min}$ after the first feeding of the day and lasted until at least 10 intact faecal pellets were obtained, usually after 1.5 to $2 \mathrm{~h}$. Three samples were usually collected per day; however, in particularly cold periods (e.g. February 2018) the bucket samples were poor due to decreased metabolism of the fish and extra material had to be retrieved from the dead fish net. The samples were screened to separate the intact faecal pellets from their broken/degraded counterparts and the uneaten feed in the bucket. The intact faecal pellets were placed in airtight containers filled with water from the fjord and transported to nearby facilities in Matre, where the resuspension tests were performed.

\subsection{Experimental setup}

Experiments to determine the resuspension parameters for the faecal pellets were performed in 3 semisubmerged tubular HDPE flumes, $2.5 \mathrm{~m}$ long and 0.36 $\mathrm{m}$ in diameter (Samsing et al. 2014, Solstorm et al. 2015). Each flume was equipped with a 2-blade Minn Kota 80 boat propeller as a flow generator and a honeycomb panel to create uniform grid turbulence across the flume's diameter (Fig. 1).

The flumes were placed inside a $7 \mathrm{~m}$ circular tank with recirculating saltwater. The water level was adjusted until the flumes were completely submerged, but sufficient maneuverability remained to enable preparing the sediments and placing the faecal material. Salinity was kept constant at $33 \%$ and the tanks were open to local environmental conditions.

Four substrate types were selected based on those used by Law et al. (2016) and the bottom types most commonly found in aquaculture production zones in Norway (Table 1). Soft substrates were retrieved from Masfjorden using a van Veen grab sampler from areas in the direct vicinity of active fish farms so that the bacterial communities and benthic invertebrates were representative of organically enriched conditions. Hard substrates were taken from commercial or local sources around the test facility in Matre. For each experiment, a $5 \mathrm{~cm}$ base layer of substrate was placed in the bottom of the flume, leveled and left undisturbed for $24 \mathrm{~h}$ so the finer material, which normally became suspended during the substrate handling, could settle again. This period was also intended to re-establish the pre-existing biogeochemical gradients in the sediment and consequently better reproduce any effect from particle age upon the resuspension process.

Each resuspension test started by placing 8 to 10 intact faecal pellets on the substrate at the start of the flume's raceway in order to register the different remobilization phenomena along the entire length of the flume. The faecal material was left to interact with the substrate for a defined period of time $(0,1,3$ or $6 \mathrm{~d}$ ) to analyze the effect of particle age on the critical resuspension threshold value. Once the desired particle age was attained, the propeller was started, and the velocity was increased in a stepwise pattern of $2-3 \mathrm{~cm} \mathrm{~s}^{-1}$ every step until reaching $30 \mathrm{~cm} \mathrm{~s}^{-1}$ or until all the faeces were flushed out of the flume. At each step, the motor's power was kept constant for between 200 and $400 \mathrm{~s}$ to collect enough data for an estimate of turbulence parameters. Tests were run in triplicate for substrate type and pellet age combination, and experiments were designed to minimize 

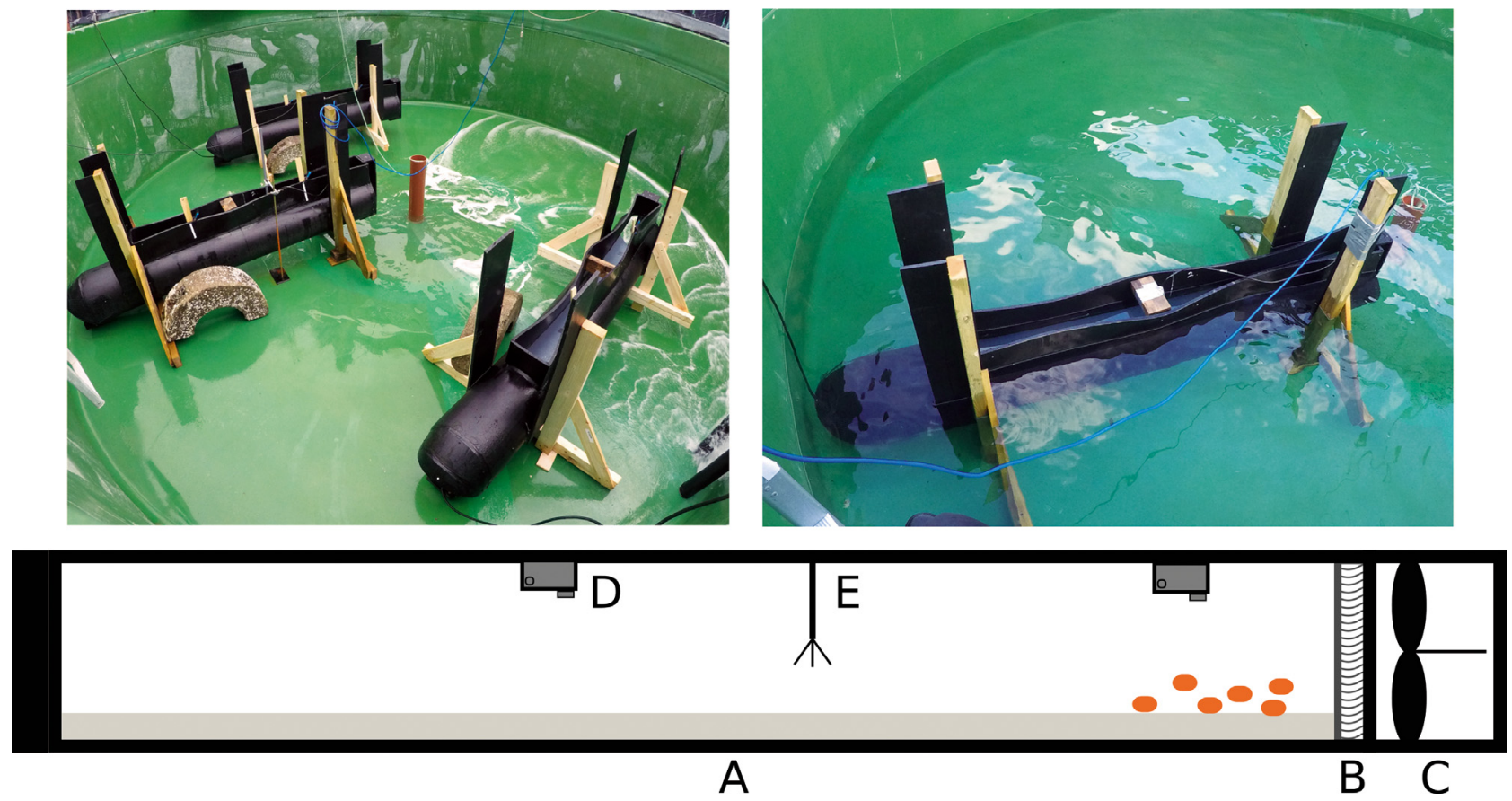

Fig. 1. Experimental setup for remobilization experiments. Intact faecal pellets (in orange) were carefully placed near the start of the raceway and inside the field of vision of the front camera to register the onset of particle movement during the stepwise increase in flow velocity. A: flume raceway; B: honeycomb panel; C: propeller; D: Go-Pro camera; E: Nortek Vectrino ADV

Table 1. Substrate types used to represent most common bottom conditions in Norwegian aquaculture production zones. $d_{50}$ : median diameter, $Z_{0}$ : bed roughness length, na: data not available

\begin{tabular}{|lcccl|}
\hline Substrate & Origin & $d_{50}(\mathrm{~mm})$ & $Z_{0}(\mathrm{~mm})$ & Source \\
\hline Mud & Masfjorden & $0.002-0.01$ & 0.2 & Soulsby (1997) \\
Rock slates & Local quarry & na & 0.3 & Lynch et al. (2015) \\
Sand & Masfjorden & $0.25-0.5$ & 0.4 & Soulsby (1997) \\
$\begin{array}{l}\text { Fragmented } \\
\text { rock }\end{array}$ & Matre's shore & $200-250$ & $10-20$ & Soulsby (1997) \\
\hline
\end{tabular}

manipulation of the substrate once it was laid in the flume. Additional sources of variability were minimized: the same flume was used for all tests on a given substrate, high velocities that would drastically erode substrates were avoided, and the substrate was re-leveled between tests in the event such erosion inadvertently occurred.

\subsection{Data acquisition}

Near-bed velocities were measured $2 \mathrm{~cm}$ above the bottom using a Nortek Vectrino ${ }^{\mathrm{TM}}$ acoustic doppler velocimeter (ADV) at $25 \mathrm{~Hz}$. Vectrino ${ }^{\mathrm{TM}}$ ADVs were selected due to their good performance measuring near-bed velocities and turbulence parameters, while the measurement distance was selected to ensure measurements were taken outside the bed interference region for this instrument (Koca et al. 2017).

Velocimeter data underwent a series of quality control and pre-processing steps. Thresholds for beam correlations and signal-to-noise ratios (SNR) were obtained using low-pass filters. Cut-off values were case-specific; however, the standard approach was to achieve an SNR >15 and a correlation above $90 \%$. Additionally, data loss over the whole dataset was kept below $25 \%$ of the raw measurements. Once data were quality controlled, the missing values were interpolated using a 3rd-order polynomial function applied to a 12-point window around the missing value according to Goring \& Nikora (2002).

Both the pre-processing and further data analysis were based on the assumption that flow was constant (i.e. one constant mean velocity value) and therefore the velocity components $(u, v, w)$ can be described via Reynolds decomposition as the sum of a mean and a fluctuating part:

$$
u=\langle u\rangle+u^{\prime}
$$

where $\langle u\rangle$ is the average velocity over time and $u^{\prime}$ is the fluctuating component. As the tests involved stepwise increases of the propeller's rotational 
speed, all results are associated with a given segment of the data where the motor power was held constant for 200-400 s, identified by the sub-index $i$ in the equations.

As a first processing step, the acceleration thresholding method from Goring \& Nikora (2002) was implemented to remove spikes from the velocity component series. These spikes can be caused by aliasing and reflection of previous beams due to complex flume geometry. The method replaces instantaneous velocities with the mean of 12 values on each side of the spike when either of the following sets of conditions is fulfilled:

$$
\begin{gathered}
a_{i j}<-\lambda_{a} g \text { and } u_{i j}<-\kappa \sigma_{i} \\
a_{i j}<\lambda_{a} g \text { and } u_{i j}<\kappa \sigma_{i}
\end{gathered}
$$

where $a_{i j}$ is the instantaneous acceleration, $u_{i j}$ is the instantaneous velocity, $g$ is the gravitational acceleration, and $\sigma_{i}$ is the standard deviation of the segment. Parameters $\lambda_{a}$ (relative acceleration threshold) and $\kappa$ (magnitude threshold factor) were given optimal values of 1 and 1.5 according to Goring and Nikora (2002).

De-spiked velocity components were rotated to a streamline coordinate system with the $x$-axis aligned with the mean flow direction, the $y$-axis with the horizontal cross section of the mean flow and the z-axis in the vertical. Once rotated, the components were detrended to obtain the fluctuating components of the velocity.

\subsection{Turbulence measurements}

Turbulence-related parameters were derived from the rotated fluctuating velocity components. The linear elements of the stress tensor, corresponding to the interaction between the horizontal and vertical components, were used for calculating the shear stresses at the sampling location (Pieterse et al. 2015):

$$
\tau_{2 \mathrm{~cm}}=\rho \sqrt{\left\langle u_{i j}^{\prime} W_{i j}^{\prime}\right\rangle^{2}+\left\langle v_{i j}^{\prime} W_{i j}^{\prime}\right\rangle^{2}}
$$

where $\rho$ is the water density and $u_{i j}^{\prime}, v_{i j,}^{\prime}, w_{i j}^{\prime}$ are the along flume, across flume and vertical fluctuating components of the near-bed velocity, respectively. Bottom shear stress $\left(\tau_{b}\right)$ and shear velocity $\left(u_{*}\right)$ were calculated using a second moment statistics method based on the Turbulent Kinetic Energy (TKE), using a proportionality constant $C_{1}$ of 0.2 :

$$
\begin{gathered}
\mathrm{TKE}=\frac{1}{2}\left(\left\langle u_{i j}^{\prime}{ }^{2}\right\rangle+\left\langle{v_{i j}^{\prime}}^{2}\right\rangle+\left\langle{w_{i j}^{\prime}}^{2}\right\rangle\right) \\
\tau_{b}=C_{1} \rho \mathrm{TKE}
\end{gathered}
$$

$$
u_{*}=\sqrt{\frac{\tau_{b}}{\rho}}
$$

This has proven to be the most consistent method to derive shear stress from ADV measurements (Kim et al. 2000).

\subsection{Image processing and analysis}

Tests were video-recorded using 2 GoPro Hero 5 cameras. The cameras were located approximately $30 \mathrm{~cm}$ (front) and $150 \mathrm{~cm}$ (back) from the honeycomb panel and held below water level to prevent surface fluctuations during the motor power increases from interfering with visibility of the particle movements. Each camera covered slightly more than $1 \mathrm{~m}$ of the flume raceway length. Both videos were synchronized with the ADV measurements and analyzed independently to determine when particles moved, as well as to verify if the particle movement was congruent as the particle moved away from the power source or if resuspension near the propeller was induced by turbulent bursts only.

Two processes were identified in the videos: saltation, when particles began being transported slowly as bedload, rolling on their own axis and keeping permanent contact with the bottom, and resuspension, when particles detached completely from the bottom and were rapidly transported by the mean flow. The results presented in the paper correspond to those of the velocity segment when each process was observed.

\subsection{Statistical analysis}

The effects of particle age and substrate type on $\tau_{c}$ were evaluated using a 2-way ANOVA in R (v. 3.4.1, R Development Core Team 2017). Shapiro-Wilk tests on the residuals were used to test for normality, and post-hoc multiple pairwise-comparisons between groups using Tukey's HSD were used to identify pairs of groups causing significant differences.

\section{RESULTS}

\subsection{Effect of substrate type and particle age on remobilization processes}

Mean near-bed velocities required for faecal pellet saltation and resuspension were extracted from the analysis of synchronized videos and grouped by sub- 
strate type and particle age (Fig. 2). The onset of the initial saltation process was observed in a relatively narrow band of values around $5.4 \pm 1.5 \mathrm{~cm} \mathrm{~s}^{-1}$ (mean $\pm \mathrm{SD}$ ), while near-bed velocities causing resuspension were much more widely distributed $(10.5 \pm$ $3.3 \mathrm{~cm} \mathrm{~s}^{-1}$ ).

Particle saltation (Fig. 2a) occurred at similar nearbed velocities for all substrates; however, smooth surfaces (mud and rock slates) showed much less variability in the velocity required to initiate saltation than the coarse substrates (sand and rock). Variability was particularly high for fragmented rock due to a shadowing effect when particles fell into cracks and fractures between the rocks. Fragmented rock also showed intra-group spread with respect to particle age levels.

A 2-way ANOVA showed no significant effect of substrate type $(p=0.450)$ or particle age $(p=0.792)$ on the onset of saltation. Therefore, a single mean near-bed velocity close to $5 \mathrm{~cm} \mathrm{~s}^{-1}$ can be used as a proxy threshold for incipient motion of faecal pellets above all bottom conditions.

The velocities at which particle resuspension occurred were much more variable than those for saltation (Fig. 2b). Faecal pellets on muddy sediments showed a consistent behavior at all age levels, with the lowest velocities for resuspension of the tested substrates. Even though rock slates were initially classified as a 'smooth surface', results show that the velocity required for particles to detach from this substrate were similar to that required for sand, and much higher than that for mud. As expected, the
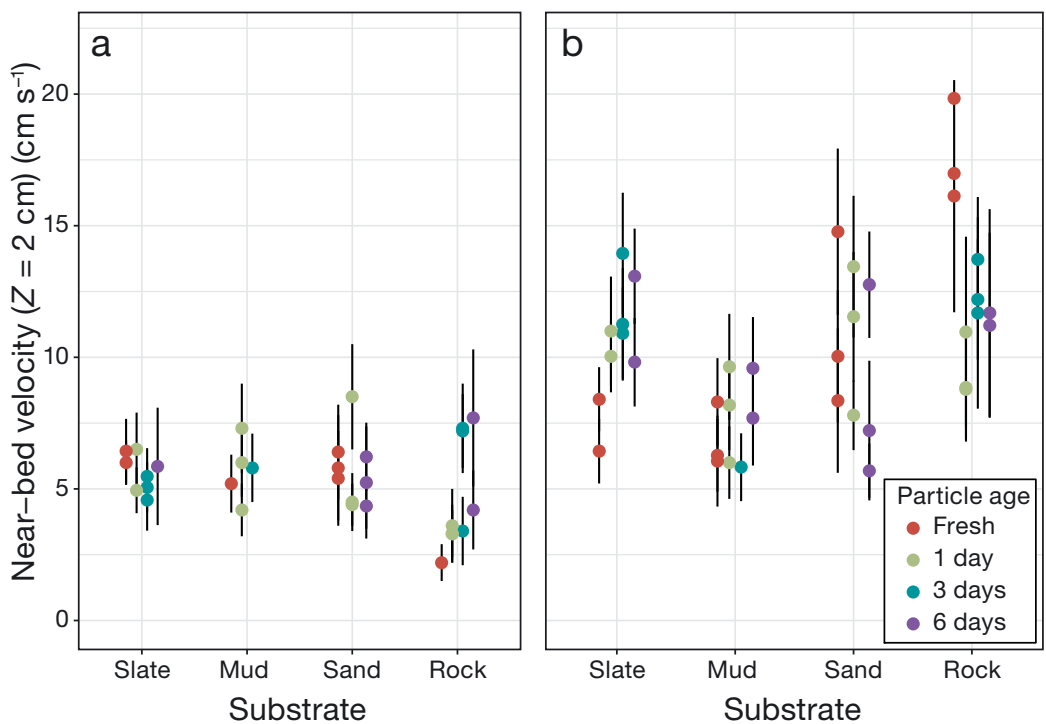

Fig. 2. Near-bed velocities for the onset of (a) particle saltation and (b) particle resuspension. Dots indicate the mean velocity per replicate, while the error bars indicate standard deviations from the mean segment speed highest velocities were needed to attain particle resuspension for the rocky substrate, mainly due to the shadowing effect of the fractures and cracks in this substrate.

Statistical analysis indicated that there were significant differences in the near-bed velocity required for resuspension among different substrate types $(p<0.001)$, but not across particle age groups $(\mathrm{p}=0.432)$. An apparent significant interaction between substrate type and age $(p=0.005)$ was also detected in the resuspension results. However, a closer look at the data revealed that fresh particles in fractured rocks had a much higher mean velocity than the rest of the tests for the same substrate. We confirmed that all particles in the fresh material tests fell into deep cracks and required very strong bursts to be re-entrained into the flow; thus, the set should be treated as an outlier. After removing this set from the analysis, the interaction between substrate type and age was no longer significant $(\mathrm{p}=$ 0.231 ) and therefore the only factor contributing to the variability in resuspension velocities was the substrate type.

The energy transfer between near-bed velocities and bottom shear stress is strongly dependent on the turbulence structure at the BBL; therefore, bottom shear stresses and shear velocities are much more robust parameters for comparing resuspension in different locations than near-bed measurements. As saltation proved to be independent of both substrate and particle age, bottom parameters were calculated for resuspension only (Table 2).

Similar to the results for near-bed velocities, the bed shear stresses and shear causing particle resuspension were significantly influenced by the substrate type, but not by the particle age. Therefore, mean values for bed shear stress of 0.06, 0.07, 0.12 and 0.32 Pa can be used as $\tau_{c}$ for particle resuspension over rock slate, mud, sand and fragmented rock substrates, respectively (Fig. 3).

Tukey post-hoc analyses indicated that main differences in critical bottom shear stress for resuspension occurred between the fragmented rock and the smooth surfaces (i.e. mud and rock slates, $\mathrm{p}<0.005$ ). Sandy bottom was not significantly different from the fragmented rocks $(\mathrm{p}=$ 0.151 ) or the smooth surfaces ( $p=0.10$ for mud, $\mathrm{p}=0.17$ for slates). However, a closer look at the inter-group differences in the Tukey test shows that the apparent 
Table 2. Bottom parameters for salmon faecal pellet resuspension derived from near-bed velocities and Reynolds shear stresses. TKE: Turbulent kinetic energy. $\tau_{b}$ : bottom shear stress; $u_{*}$ : shear velocity. Values reported as na are not available due to experimental errors

\begin{tabular}{|c|c|c|c|c|c|}
\hline Substrate & $\begin{array}{l}\text { Particle age } \\
\text { (d) }\end{array}$ & TKE $\left(\mathrm{m}^{2} \mathrm{~s}^{-2}\right)$ & $\tau_{b}(\mathrm{~Pa})$ & $u_{*}\left(\mathrm{~mm} \mathrm{~s}^{-1}\right)$ & $\begin{array}{l}\text { Viscous sublayer } \\
\text { thickness (mm) }\end{array}$ \\
\hline Rock slates & $\begin{array}{c}0 \\
1 \\
3 \\
6 \\
\text { Mean } \pm \text { SD }\end{array}$ & $\begin{array}{c}1.4 \times 10^{-4} \\
3.0 \times 10^{-4} \\
4.1 \times 10^{-4} \\
2.8 \times 10^{-4} \\
(3.0 \pm 1.3) \times 10^{-4}\end{array}$ & $\begin{array}{c}0.029 \\
0.061 \\
0.085 \\
0.057 \\
0.061 \pm 0.027\end{array}$ & $\begin{array}{c}5.4 \\
7.5 \\
9.0 \\
7.4 \\
7.5 \pm 1.7\end{array}$ & $\begin{array}{c}1.9 \\
1.3 \\
1.3 \\
1.2 \\
1.4 \pm 0.4\end{array}$ \\
\hline Mud & $\begin{array}{c}0 \\
1 \\
3 \\
6 \\
\text { Mean } \pm \text { SD }\end{array}$ & $\begin{array}{c}2.7 \times 10^{-4} \\
3.4 \times 10^{-4} \\
4.4 \times 10^{-4} \\
3.8 \times 10^{-4} \\
(3.4 \pm 1.1) \times 10^{-4}\end{array}$ & $\begin{array}{c}0.055 \\
0.070 \\
0.090 \\
0.078 \\
0.069 \pm 0.020\end{array}$ & $\begin{array}{c}7.3 \\
8.2 \\
9.4 \\
8.8 \\
8.1 \pm 1.2\end{array}$ & $\begin{array}{c}1.7 \\
1.6 \\
1.3 \\
1.1 \\
1.4 \pm 0.3\end{array}$ \\
\hline Sand & $\begin{array}{c}0 \\
1 \\
3 \\
6 \\
\text { Mean } \pm \text { SD }\end{array}$ & $\begin{array}{c}8.8 \times 10^{-4} \\
5.8 \times 10^{-4} \\
\text { na } \\
3.6 \times 10^{-4} \\
(6.1 \pm 3.3) \times 10^{-4}\end{array}$ & $\begin{array}{c}0.180 \\
0.120 \\
\text { na } \\
0.075 \\
0.125 \pm 0.068\end{array}$ & $\begin{array}{c}13.2 \\
10.3 \\
\text { na } \\
8.1 \\
10.5 \pm 3.5\end{array}$ & $\begin{array}{c}0.8 \\
1.3 \\
\text { na } \\
1.6 \\
1.2 \pm 0.6\end{array}$ \\
\hline $\begin{array}{l}\text { Fragmented } \\
\text { rock }\end{array}$ & $\begin{array}{c}0 \\
1 \\
3 \\
6 \\
\text { Mean } \pm \text { SD }\end{array}$ & $\begin{array}{c}3.3 \times 10^{-3} \\
6.3 \times 10^{-4} \\
7.8 \times 10^{-4} \\
1.5 \times 10^{-3} \\
(1.6 \pm 1.4) \times 10^{-3}\end{array}$ & $\begin{array}{c}0.681 \\
0.130 \\
0.160 \\
0.305 \\
0.061 \pm 0.027\end{array}$ & $\begin{array}{c}25.3 \\
10.7 \\
12.2 \\
17.2 \\
16.3 \pm 7.3\end{array}$ & $\begin{array}{c}0.4 \\
1.1 \\
0.9 \\
0.6 \\
0.8 \pm 0.3\end{array}$ \\
\hline
\end{tabular}

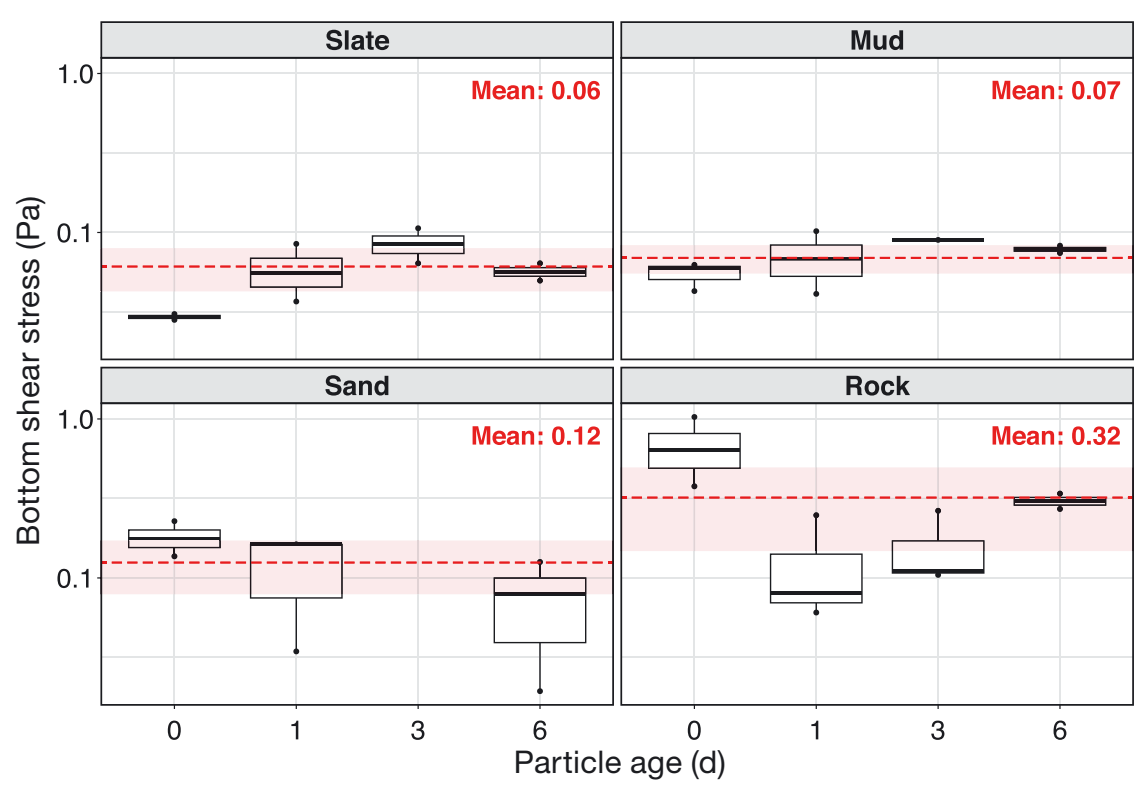

Fig. 3. Critical shear stress for resuspension of $0,1,3$, and 6 d old faecal pellets over different substrates. The dotted red line shows the mean critical shear stress for resuspension over each substrate, and red-shaded areas around the mean are $95 \%$ percentiles based on a normal distribution. A log-scale is used for the $y$-axis due to the 10 -fold difference in critical shear stress between the soft and coarse substrates

similarity of the sand with both other groups is supported only by the extreme values, and thus should be subject to further consideration in the light of the scale-limitations of the experimental setup and the flow structures inside the flumes.

\subsection{Flow and turbulence structure inside the flumes}

Velocity profiling tests in the flumes indicated that, even with the use of the honeycomb panel, the velocity (and consequently turbulence) distribution was not completely uniform along the flume's diameter, homogenizing between 80 and $90 \mathrm{~cm}$ from the start of the flume raceway (Fig. 4). Therefore, the use of a 2-camera verification system, with cameras at the front and the back of the flume, was mandatory to validate that the particle movement was congruent along the flume.

ADV measurements showed marked spikiness and strong deviations from the segment averages (Fig. 5), which is to be expected for high-frequency acoustic measurements in highly dynamic environments (e.g. inside the BBL). Velocity records close to the shifts in propeller's rotation (blue dots in Fig. 5) were characterized by strong gradients and sometimes large pulses that require some time to stabilize. Therefore, these transition periods were excluded from the analyses. 


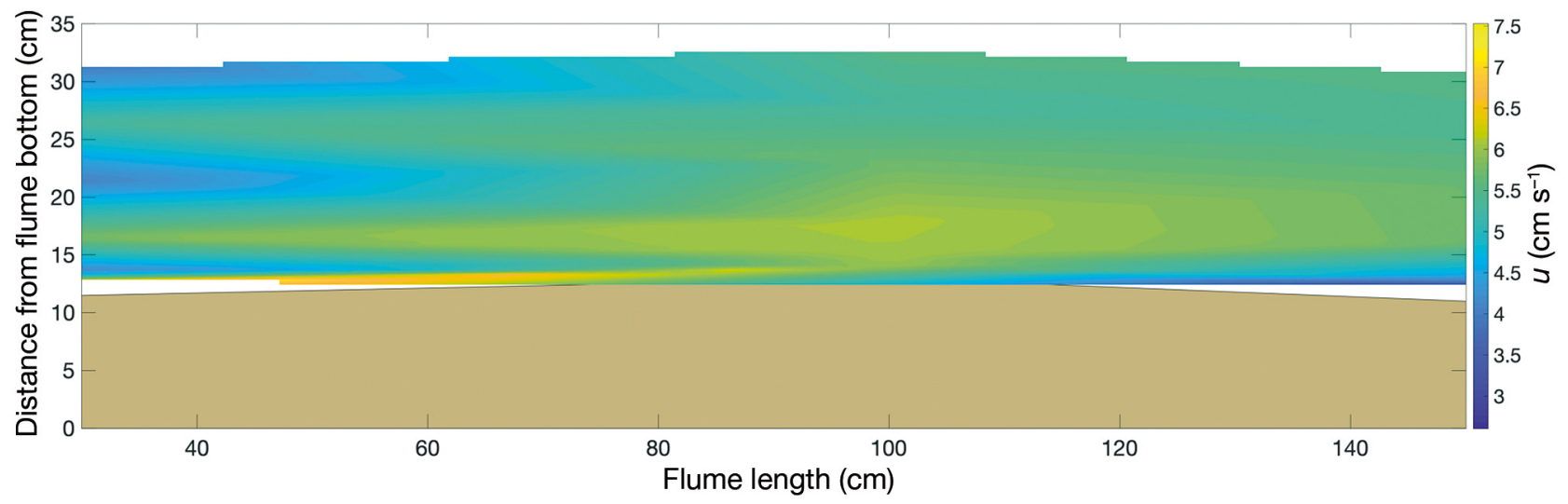

Fig. 4. Velocity profile over a sandy bottom. The influence of the propeller is evident in the first part of the flume as 2 symmetric high velocity lobes. A near homogeneous vertical distribution of velocities is attained around $80 \mathrm{~cm}$ from the honeycomb panel. The light brown area indicates the bottom substrate, while the white areas were not covered during the sampling

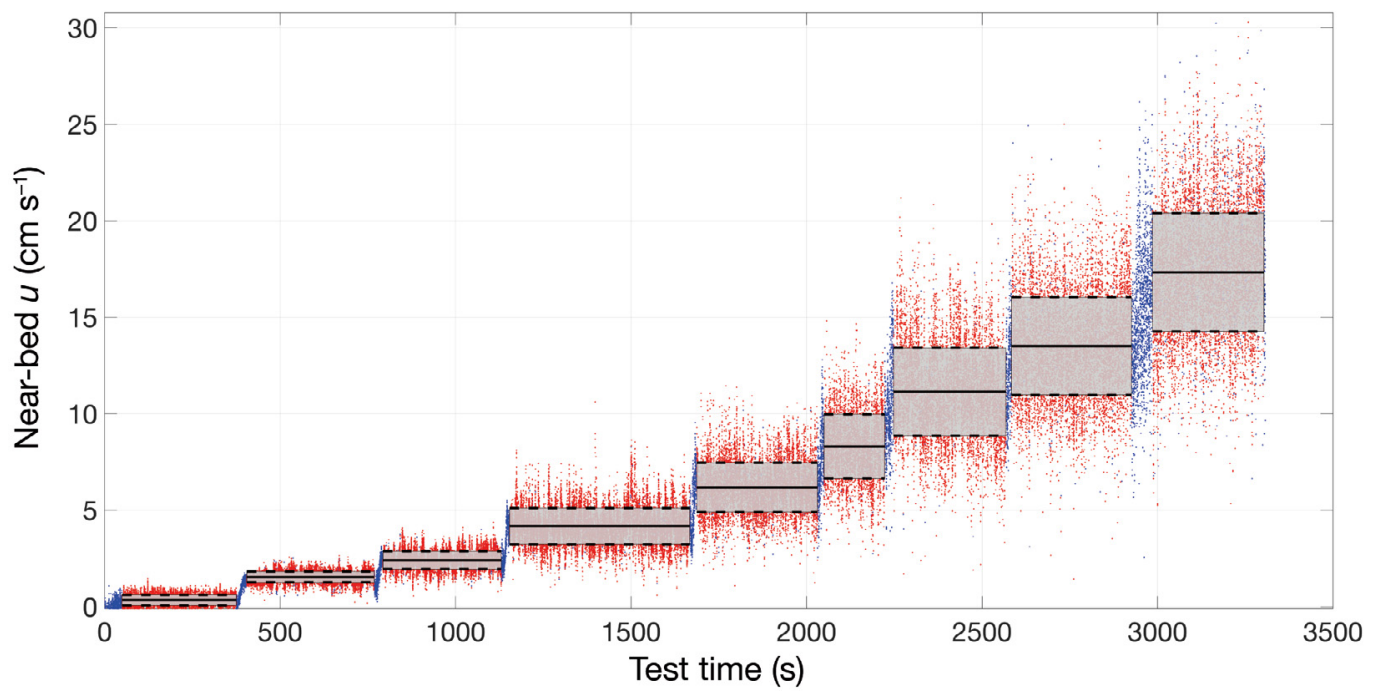

Fig. 5. Raw (blue) and processed (red) velocity records for the main velocity component during a test over muddy substrate. The black lines and grey boxes indicate the mean $\pm \mathrm{SD}$ of the corrected values, representing the constant motor power segments

We observed a turbulence-development pattern in the energy spectra of most of the experiments, where mean near-bed velocities lower than $2 \mathrm{~cm} \mathrm{~s}^{-1}$ did not comply with Kolmogorov's 5/3 slope homogeneous turbulence hypothesis at the inertial sub-range (Fig. 6). This indicates that at these low velocities, turbulence is not fully developed, and the flow might still be in the laminar to transition Reynold numbers.

Incipient motion of the faecal pellets (i.e. particle saltation) was almost always observed in the videos at near-bed velocities higher than the threshold where flow became fully turbulent and the spectra complied with Kolmogorov's 5/3 theory. This can be related to the higher skin friction drag caused by shear stresses when compared to laminar flow, causing much larger tangential forces on the particle.

\section{DISCUSSION}

Our findings indicate that the critical shear stress $\left(\tau_{c}\right)$ required to resuspend intact faecal pellets from salmon fish farming is strongly substrate-dependent, becoming higher as substrate materials become coarser. We determined $\tau_{c}$ values of 0.06-0.07 Pa for faecal material sitting on smooth substrates (i.e. muds and rock slates), which differed significantly from the value of $0.32 \mathrm{~Pa}$ required to resuspend the faeces on fractured rocky substrates. Faeces settled on sand, a very common substrate type for farms in exposed locations, required a $\tau_{c}$ close to $0.12 \mathrm{~Pa}$. Although we did not find a statistically significant difference between the sand and the 2 other substrate groups, we consider there is enough evidence to treat sand sepa- 


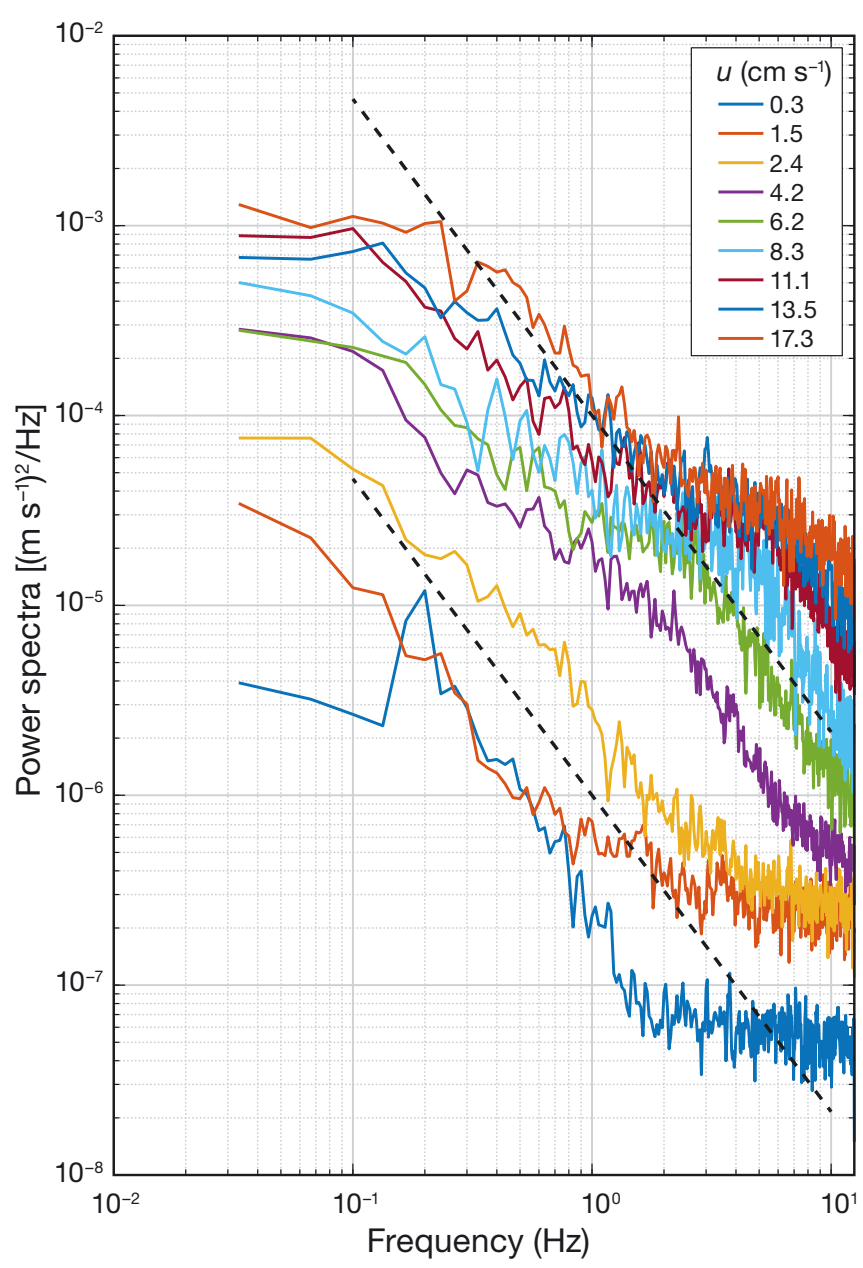

Fig. 6. Energy spectra for the $u$ component of the velocity over a mud substrate. Flow begins to exhibit Kolmogorov's 5/3slope theory in the inertial subrange after near-bed velocities exceed $2 \mathrm{~cm} \mathrm{~s}^{-1}$ along the main axis. A noise floor value close to $5 \times 10^{-7}\left(\mathrm{~m} \mathrm{~s}^{-1}\right)^{2} \mathrm{~Hz}^{-1}$ can be observed for the lowest velocity values, occurring when the motor was off. A 5 -fold increase in noise occurred with the onset of the propeller

rately when implementing substrate-dependency in numerical models for resuspension.

Even though the faeces sampling and handling methods were intended to minimize particle breakdown, at least some of the detected differences between the substrates could be attributed to differences in faecal pellet size. Even though we assume that the influence of pellet size is integrated into the reported $\tau_{c}$ values, further work should include detailed characterization of the size and composition of the pellets, to analyze whether these factors have a significant influence on resuspension thresholds.

Surprisingly, no significant effect of particle age was found for up to 1 week old faecal pellets, even though our experimental setup was open to the environment and thus exposed to larger thermal gradi- ents than those expected on the seabed, which constitutes a potential driver for heightened levels of bacterial activity, and we observed some swelling and loss of structural integrity during some of the longest ( $6 \mathrm{~d}$ ) tests. One possible reason for the lack of a significant age effect is the short acclimation period given to the sediments to re-establish their biogeochemical gradients after laying them inside the flumes (i.e. $24 \mathrm{~h}$ ); the recovery of bacterial and benthic communities after a large-scale sediment disturbance might take much longer. This could lead to sub-optimal conditions in the biological communities and therefore much lower rates of interaction with the particles during the experiments than in longstanding sediments in real aquaculture locations.

Video surveys in salmon farming sites have shown us that there is an important portion of faecal pellets that sits on the bottom as broken-down faeces. Our results appear to indicate that the breaking down is not caused by swelling or thermal or bacterial degradation, but rather by other factors such as physical shear during the initial settling process, grazing by benthic organisms, and the cumulative effect of short-lived resuspension/settling episodes, where drag forces gradually shed material from the faecal pellets until the mucous layer breaks apart and the pellet structure is lost. Our results are not directly applicable to this fraction of broken-down faecal material, as their high variability in shape and composition will strongly impact the critical shear stress required to resuspend them, most certainly requiring lower values of $\tau_{c}$ such as those reported by Law et al. (2016).

The results of our study contrast with those of Cromey et al. (2002b) and Law et al. (2016), both of whom described single $\tau_{c}$ values for the resuspension of faecal material. The apparent disparity between these studies and our own arises primarily from the use of very different materials during the resuspension tests. Cromey et al. (2002b) used dummy tracer particles with a diameter of 2 to $6 \mathrm{~mm}$, a settling velocity of approximately $3.4 \mathrm{~cm} \mathrm{~s}^{-1}$ and a specific gravity of 1.127 , which they state correspond to the physical characteristics of fish farm wastes. In contrast, Law et al. (2016) used real faecal material taken from a fish hatchery.

Faecal pellets have been reported to be much larger and heavier than the particles Cromey et al. (2002b) used during their experiments, with at least half of the particles having a diameter larger than 8 mm (e.g. Buryniuk et al. 2006, Bannister et al. 2016, Broch et al. 2017). Field measurements during this study agree quite well with those reported by Ban- 
nister et al. (2016) for salmon farms at Hardangerfjorden (Norway), with diameters between 8 and $10 \mathrm{~mm}$ and settling velocities ranging from 2.5 to $10 \mathrm{~cm} \mathrm{~s}^{-1}$. Cromey et al. (2002b) indicated their results were in the lower end of previously reported $\tau_{c}$ for resuspension, which suggest that the threshold of 0.018 Pa might not be adequate for intact faeces but would be appropriate for the finer fraction of brokendown material that can also be found on the seafloor near the farms. This is reinforced by the overestimation of the rates of erosion in several implementations of the DEPOMOD model in the literature. Our results indicate much higher values of $\tau_{c}$ even for smooth substrates, which better match Law et al.'s (2016) observations for uneaten feed, and could indicate that the shape and integrity of the pellets play a major role in the magnitude of the shear forces required to mobilize them.

Cromey et al. (2002b) attempted to determine a resuspension stress valid for general particulate fish farm waste, i.e. encompassing both feed pellets and fish faeces. This approach is not recommended, as these wastes differ significantly both in shape and composition; therefore, it is to be expected their resuspension criteria will also be different, as shown by Law et al. (2016).

However, even though Law et al. (2016) used real faeces during their experiments, their material was composed mostly of broken-down pellets and flocculent material, as can be observed in their Fig. S2. Assuming the authors sampled the material from adult fish in the hatchery, this type of degraded material has been described by Reid et al. (2009) as typical for land-based, recirculation or flow-through systems, and not necessarily representative of conditions in sea cages. Based on the principles for resuspension of non-cohesive materials, a simplified but valid approach for intact faecal pellets if we disregard temporarily the effect of aggregation or biological interactions of the material with the substrate, we recognize that shear stress decreases proportionally with particle size. Therefore, it is logical that Law et al.'s (2016) results converge at a relatively low shear stress value for flocculent-size material while a substrate-dependency becomes evident for larger and more structurally sound uneaten feed, indicating a size-bias in their proposed value of $0.01 \mathrm{~Pa}$ as the incipient $\tau_{c}$ for particle motion.

Another potential source of bias in the existing studies arises from changes in faecal pellet size and composition during the fish growth cycle. Bannister et al. (2016) reported that there were differences in pellet size among 3 size classes of Atlantic salmon, with larger faeces coming from larger fish. Their study also reported that all groups showed the same right-skewed distribution of pellet size and organic matter content. The tests performed in our study were based in only one fish size $(2 \mathrm{~kg})$, and therefore we recommend that further studies addressing fish faeces characteristics and resuspension explore the influence of the fish life cycle on their controlling parameters. However, we consider that, even if interesting, differences in faeces size and composition during the fish life cycle play a minor role compared with other sources of variability (e.g. inaccuracies in hydrodynamic fields, model resolution, detailed vertical transport algorithms) when developing transport models for this material. Therefore, future efforts in model development might better focus on reproducing general features like the empirical rightskewed distribution of settling velocities described by Bannister et al. (2016) when defining faeces characteristics in the simulations.

An additional outcome from our study shows that intact faecal material from salmon fish farms can be initially mobilized very slowly as bedload when a constant near-bed velocity of around $5 \mathrm{~cm} \mathrm{~s}^{-1}$ is attained, independent of the substrate where the particle is deposited or the age of the particle. Although interesting, this finding has limited applicability at the scale of interest for numerical simulation of aquaculture impact (on the order of $10 \mathrm{~s}$ of $\mathrm{km}$ ), as the bedload transport is much slower than the resuspension process and the distances particles travel are negligible relative to the overall footprint extent.

It is important to also consider the biological effects of the benthic communities on the fate of deposited faecal material. Cromey et al. (2002b) reported no penetration below $2 \mathrm{~cm}$ of their tracer into the sediment after $30 \mathrm{~d}$, concluding that all transport happens in the sediment surface layer. However, their tracer was not biologically active, unlike faecal pellets. Recent studies have demonstrated that many species interact with fish farming wastes at bacterial, sessile and mobile benthic levels (Woodcock et al. 2018, Keeley et al. 2019). Among the many interactions reported, we can mention direct consumption, bioturbation and active dragging of waste material into substrate burrows, which adds an extra source/sink of both horizontal and vertical dispersion of mass in the balance equations. Therefore, future modelling efforts should not overlook the importance of these effects and should assess the scale of them both in the magnitude and extent of carbon footprints.

Even though near-bed velocities are good proxies for particle remobilization, a clear definition of the 
term 'near-bed' is paramount to avoid misunderstandings among the existing literature for particle resuspension. Existing studies often fail to report clearly the height at which the measurements were done. The information on velocity characteristics and turbulence structure has to be translated in terms of bottom shear stresses and shear velocities, which can be derived easily from the velocity fields in the bottom layer of a hydrodynamic model by diverse available BBL subroutines and therefore directly compared to critical thresholds defined in laboratory studies.

Irregularities in substrate surface cause strong changes in the fluid velocity directly above the bottom. Therefore, a lot of attention was given to adequately flattening the substrate after placing it inside the flume and attaining a homogeneous $5 \mathrm{~cm}$ layer across the whole raceway. However, exposure to very high velocities near the end of each experiment caused evident erosion and generation of bedforms such as ripples and depressions in the soft sediments. Even with bed readjusting before each new test, the cumulative shadowing effect of these bedforms was evident in some of the experiments, causing additional variability between replicates. In real farming locations, such features can act as barriers that divert the micro-scale eddies and accumulate organic material on their lee side, generating organic enrichment hotspots (biodeposits) and eventually creating hypoxic conditions.

During our experiments, erosion of bottom material at high mean velocities tended to generate bedforms in the soft sediments. These ripples and depressions acted as barriers against the drag forces that nearbed flows exerted on the particles, increasing the required bed shear stresses for resuspension and causing local micro-scale eddies that trapped the particles until they were dissipated by a strong velocity gradient.

The impact of bed heterogeneity was evident in the case of fractured rocks or cobbles. As this material is very loose, large fractures or spaces can appear between elements and allow particle accumulation during the spread of the material on the bottom. Once a particle falls into a crack, very large shear stresses are needed to remove it. This effect was reported by Law et al. (2016) during their gust chamber tests, and also evidenced by the authors via video surveys at several aquaculture sites in Norway, where particles accumulated inside rock clusters and depressions in soft sediments. Considering that rocky substrate is most common in fjords, where near-bed velocities are usually lower than in more exposed locations, it is plausible that particles that land on fractured rocky beds will stay in the area indefinitely, creating hubs for organic enrichment.

As stated at the beginning of the discussion, the $\tau_{C}$ required for resuspension appears to increase with the coarseness of the substrate the faeces sit on. This pattern can be partly attributed to greater friction between the bottom and the particle; however, we consider the turbulence-driven thinning of the viscous sublayer on coarser substrates to be a major factor in the onset of the process. The relationship between critical shear and frictional forces makes it plausible to find an empirical function linking $\tau_{c}$ to a length scale, such as the bed roughness length $\left(Z_{0}\right)$, which describes the frictional effects induced by the substrate on the near-surface flow. In order to determine such a function and extend our $\tau_{c}$ results to a continuous range of substrate roughness, future work will need to explore additional substrates beyond those in these study, particularly mixed media such as sand and gravel, or sand and shells, which are very common in coastal aquaculture locations. This will make it possible to create substrate-dependent resuspension models not only for areas with substrates similar to the 4 types presented in this study, but over the whole coast of Norway.

The limitations discussed above do not imply that the previously reported low values of $\tau_{c}$ for salmon waste are invalid, but rather that these values are applicable only to the lower end of the size distribution of faecal material on salmon fish farms, typically only the broken-down fraction of the faeces. Larger particle wastes, such as intact faecal pellets (this study) and feed pellets (Law et al. 2016), have shown a strong substrate-dependency in resuspension and very similar values of $\tau_{C}$ for selected substrates. Therefore, it is a natural further step in the development of aquaculture waste dispersion models to recognize that different particle types have different behaviors, and the recently identified sets of substrate-dependent $\tau_{c}$ values must be integrated into the existing toolboxes. We expect that the addition of our substratedependent $\tau_{c}$ values for the resuspension of intact faecal pellets to the current modelling tools will help to obtain better projections of farm footprints and biological enrichment of the benthic communities surrounding aquaculture production zones.

\section{CONCLUSIONS AND RECOMMENDATIONS}

We identified a significant substrate-dependency in the critical shear stress $\left(\tau_{c}\right)$ values required to re- 
suspend intact faecal pellets from salmon fish farms. Based on our results, we recommend the use of 3 threshold values of $\tau_{c}$ when integrating our results into particle transport models for the salmon-farming industry in Norway. Smooth substrates such as mud and rock slates require relatively low $\tau_{c}(0.06-0.07 \mathrm{~Pa})$ to resuspend the faecal pellets, whereas values for sand $(0.12 \mathrm{~Pa})$ and fragmented rocks/cobblestones (0.32 Pa) are higher, which should be implemented separately.

Previous shear stress values from Cromey et al. (2002b) and Law et al. (2016) should be used with caution when modelling intact faecal pellets, as pellet characteristics differ substantially from the material used during their tests. However, the low shear values found in these studies may still be representative for the finer fraction of the faecal material produced at the fish farm and our recommendation for model implementation is to use a mixed approach with substrate-dependent values of shear stress for the bulk of the faecal material and a single lower constant value for the finer fraction.

A natural extension of the present research would be to perform further experiments with more detailed classification of the substrates, linking the obtained critical shear stresses to a continuous variable such as the surface roughness length $\left(Z_{0}\right)$, which represents the resistance of bottom to drag. By expressing such link as a regression equation, critical stress zones could be obtained from detailed substrate type maps from national bathymetric surveys. Similarly, future studies could take the influence of pellet size variability into account in their analyses to identify whether there is an interaction between the effect of substrate and particles on critical shear stress.

Future steps for this research include the implementation of the reported substrate-dependent threshold values in a Lagrangian model using individual based modelling (IBM), as well as the IBM's validation against field observations of the extent of the farm footprint on different substrates.

Acknowledgements. This study was supported by the Norwegian Research Council through the ERA research platform (project number: 228871). The authors would like to thank all the personnel at IMR's Matre research station and Smørdalen experimental fish farm for their constant help during experiments, particularly J. O. Fosse, K. Dahle, J. H. Nordahl, J. Eikeland and M. Larsen for their assistance during the sampling process. We would also like to thank Raúl Villanueva (LUH-LUFI) for his insight on the use of the Vectrino ${ }^{\mathrm{TM}} \mathrm{ADVs}$ for near-bed applications.

\section{LITERATURE CITED}

Bannister RJ, Valdemarsen T, Hansen PK, Holmer M, Ervik A (2014) Changes in benthic sediment conditions under an Atlantic salmon farm at a deep, well-flushed coastal site. Aquacult Environ Interact 5:29-47

*Bannister RJ, Johnsen IA, Hansen PK, Kutti T, Asplin L (2016) Near- and far-field dispersal modelling of organic waste from Atlantic salmon aquaculture in fjord systems. ICES J Mar Sci 73:2408-2419

Black KD (2001) Environmental impacts of aquaculture, Vol 1. Sheffield Academic Press, Sheffield

Boudreau BP, Jørgensen BB (2001) The benthic boundary layer: transport processes and biogeochemistry. Oxford University Press, Oxford

Broch OJ, Daae RL, Ellingsen IH, Nepstad R, Bendiksen EÅ, Reed JL, Senneset G (2017) Spatiotemporal dispersal and deposition of fish farm wastes: a model study from central Norway. Front Mar Sci 4:199

* Brooks KM, Mahnken CV (2003) Interactions of Atlantic salmon in the Pacific northwest environment: II. Organic wastes. Fish Res 62:255-293

* Buryniuk M, Petrell RJ, Baldwin S, Lo KV (2006) Accumulation and natural disintegration of solid wastes caught on a screen suspended below a fish farm cage. Aquacult Eng 35:78-90

* Chamberlain J, Stucchi D (2007) Simulating the effects of parameter uncertainty on waste model predictions of marine finfish aquaculture. Aquaculture 272:296-311

* Chang BD, Page FH, Losier RJ, McCurdy EP (2014) Organic enrichment at salmon farms in the Bay of Fundy, Canada: DEPOMOD predictions versus observed sediment sulfide concentrations. Aquacult Environ Interact 5:185-208

* Cromey CJ, Nickell TD, Black KD (2002a) DEPOMOD modelling the deposition and biological effects of waste solids from marine cage farms. Aquaculture 214:211-239

* Cromey CJ, Nickell TD, Black KD, Provost PG, Griffiths CR (2002b) Validation of a fish farm waste resuspension model by use of a particulate tracer discharged from a point source in a coastal environment. Estuaries 25: 916-929

Cubillo AM, Ferreira JG, Robinson SMC, Pearce CM, Corner RA, Johansen J (2016) Role of deposit feeders in integrated multi-trophic aquaculture - a model analysis. Aquaculture 453:54-66

FAO (2018) The state of world fisheries and aquaculture 2018: meeting the sustainable development goal. FAO, Rome

Garcia SM, Grainger RJ (2005) Gloom and doom? The future of marine capture fisheries. Philos Trans R Soc B 360: $21-46$

Goring DG, Nikora VI (2002) Despiking acoustic doppler velocimeter data. J Hydraul Eng 128:117-126

Johnsen IA, Asplin LC, Sandvik AD, Serra-Llinares RM (2016) Salmon lice dispersion in a northern Norwegian fjord system and the impact of vertical movements. Aquacult Environ Interact 8:99-116

Kaftori D, Hetsroni G, Banerjee S (1995) Particle behavior in the turbulent boundary layer: I. Motion, deposition, and entrainment. Phys Fluids 7:1095-1106

Keeley NB, Cromey CJ, Goodwin EO, Gibbs MT, Macleod CM (2013a) Predictive depositional modelling (DEPOMOD) of the interactive effect of current flow and resuspension on ecological impacts beneath salmon farms. Aquacult Environ Interact 3:275-291 
Keeley NB, Forrest BM, Macleod CK (2013b) Novel observations of benthic enrichment in contrasting flow regimes with implications for marine farm monitoring and management. Mar Pollut Bull 66:105-116

Keeley N, Valdemarsen T, Woodcock S, Holmer M, Husa V, Bannister R (2019) Resilience of dynamic coastal benthic ecosystems in response to large-scale finfish farming. Aquacult Environ Interact 11:161-179

Kim SC, Friedrichs CT, Maa JPY, Wright LD (2000) Estimating bottom stress in tidal boundary layer from acoustic doppler velocimeter data. J Hydraul Eng 126:399-406

Koca K, Noss C, Anlanger C, Brand A, Lorke A (2017) Performance of the Vectrino Profiler at the sediment-water interface. J Hydraul Res 55:573-581

Kutti T, Ervik A, Hansen PK (2007) Effects of organic effluents from a salmon farm on a fjord system: I. Vertical export and dispersal processes. Aquaculture 262:367-381

Law BA, Hill PS, Milligan TG, Zions V (2016) Erodibility of aquaculture waste from different bottom substrates. Aquacult Environ Interact 8:575-584

Luckner T (2002) Zum Bewegungsbeginn von Sedimenten. PhD thesis, Technische Universität Darmstadt

Lynch DR, Greenberg DA, Bilgili A, McGillicuddy JDJ, Manning JP, Aretxabaleta AL (2015) Particles in the coastal ocean: theory and applications. Cambridge University Press, New York, NY

Martinez-Porchas M, Martinez-Cordova LR (2012) World aquaculture: environmental impacts and troubleshooting alternatives. ScientificWorldJournal 2012:389623

Nielsen P (1993) Turbulence effects on the settling of suspended particles. J Sediment Res 63:835-838

Norwegian Ministry of Fisheries and Coastal Affairs (2009) Strategy for an environmentally sustainable Norwegian aquaculture industry, Oslo

Olafsen T, Winther U, Olsen Y, Skjermo J (2012) Verdiskaping basert på produktive hav i 2050, DKNVS-NTVA, Norwegian Ministry of Fisheries and Coastal Affairs, Oslo

Pearson TH, Rosenberg R (1978) Macrobenthic succession in relation to organic enrichment and pollution of the marine environment. Oceanogr Mar Biol Annu Rev 16:229-311

Pieterse A, Puleo JA, McKenna TE, Aiken RA (2015) Nearbed shear stress, turbulence production and dissipation in a shallow and narrow tidal channel. Earth Surf Process Landf 40:2059-2070

R Development Core Team (2017) R: a language and envi-

Editorial responsibility: Jonathan Grant,

Halifax, Nova Scotia, Canada ronment for statistical computing. R Foundation for Statistical Computing, Vienna

Reid GK, Liutkus M, Robinson SMC, Chopin TR, and others (2009) A review of the biophysical properties of salmonid faeces: implications for aquaculture waste dispersal models and integrated multi-trophic aquaculture. Aquacult Res 40:257-273

Samsing F, Oppedal F, Johansson D, Bui S, Dempster T (2014) High host densities dilute sea lice Lepeophtheirus salmonis loads on individual Atlantic salmon, but do not reduce lice infection success. Aquacult Environ Interact 6:81-89

Silvert W, Sowles JW (1996) Modelling environmental impacts of marine finfish aquaculture. J Appl Ichthyology 12:75-81

Solstorm F, Solstorm D, Oppedal F, Fernö A, Fraser TWK, Olsen RE (2015) Fast water currents reduce production performance of post-smolt Atlantic salmon Salmo salar. Aquacult Environ Interact 7:125-134

Soulsby R (1997) Dynamics of marine sands. Thomas Thelford, London

Stucchi D, Sutherland TA, Levings C, Higgs D (2005) Nearfield depositional model for salmon aquaculture waste. In: Hargrave BT (ed) Environmental effects of marine finfish aquaculture. Springer, Berlin, p 157-179

Trowbridge JH, Lentz SJ (2018) The bottom boundary layer. Annu Rev Mar Sci 10:397-420

*Weise AM, Cromey CJ, Callier MD, Archambault P, Chamberlain J, McKindsey CW (2009) Shellfish-DEPOMOD: Modelling the biodeposition from suspended shellfish aquaculture and assessing benthic effects. Aquaculture 288:239-253

*Wilding TA, Cromey CJ, Nickell TD, Hughes DJ (2012) Salmon farm impacts on muddy-sediment megabenthic assemblages on the west coast of Scotland. Aquacult Environ Interact 2:145-156

Whoodcock SH, Strohmeier T, Strand Ø, Olsen SA, Bannister RJ (2018) Mobile epibenthic fauna consume organic waste from coastal fin-fish aquaculture. Mar Environ Res $137: 16-23$

World Bank (2013) Fish to 2030: prospects for fisheries and aquaculture, Washington, DC

*Wu RSS (1995) The environmental impact of marine fish culture: towards a sustainable future. Mar Pollut Bull 31: 159-166

Submitted: August 15, 2019; Accepted: January 10, 2020 Proofs received from author(s): March 23, 2020 